\title{
The Influence of Mere Exposure on Web Based Breadcrumb Navigation
}

\author{
S.S. Hull, B.S. Chaparro, and C.G. Halcomb \\ Department of Psychology, College of Liberal Arts and Sciences
}

\section{Introduction}

A breadcrumb trail is a textual representation of a user's location in a site's structure, e.g., $\underline{\text { Home }}>$ Furniture $>$ Chairs $>$ Leather Chairs. Research has reported that breadcrumb navigation improves site efficiency $[1,2]$. However, when given a choice, users choose the Back button or navigation bar to navigate rather than the breadcrumb trail [3]. Lida-Rogers \& Chaparro (2003) found that participants who used the breadcrumb trail used the Back button less often than users who did not use it; however, no differences were found in other efficiency measures such as total pages visited or total time. Participants may not understand the function of the breadcrumb trail as a navigational tool and understanding its' purpose or minimal training might impact usage and/or efficiency [4]. Mere exposure was considered as a means of introducing participants to breadcrumb trails. According to Zajonc (1968), if the function of orienting behavior is eventually to change a novel stimulus into a familiar one, it is also its consequence to render the stimulus object eventually more attractive [5]. Zajonc (1968) states that the mere repeated exposure of the individual to a stimulus object enhances his attitude toward it [5]. Thus, it was hypothesized that mere exposure of the breadcrumb trail would influence participants' use of breadcrumb trail navigation during a search task procedure.

\section{Purpose}

Participants were randomly assigned to one of three conditions. Participants in condition I received both exposure and instruction to use breadcrumb navigation. Participants in condition II received only mere exposure to the use of breadcrumb navigation. And finally, participants in condition III received neither exposure nor instruction to use breadcrumb navigation.

\section{Methods}

\section{Participants}

Thirty-nine college students (12 males and 27 females) with an average age of 23 (range 18 to 48) volunteered for this study. Eighty-two percent estimated spending time on the Internet at least once a day.

\section{Materials}

The Wal-Mart ${ }^{\circledR}$ website was chosen for examination as a breadcrumb trail is one method of navigation.

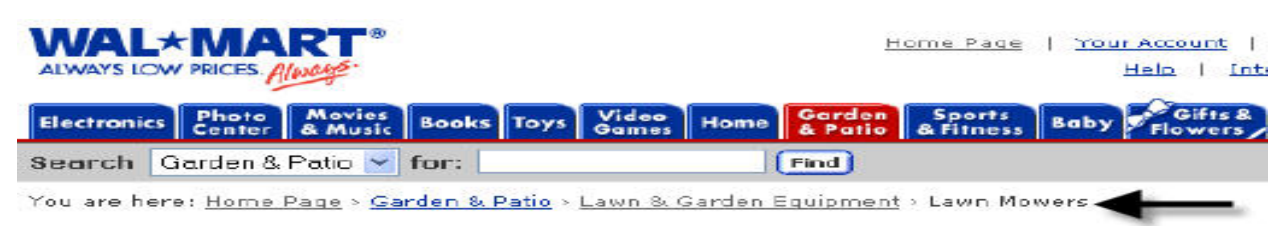

Figure 1. Breadcrumb trail used on Wal-Mart ${ }^{\circledR}$ site.

\section{Task Design/Procedure}

Participants were given a 13- item shopping list of items available at Wal-Mart ${ }^{\circledR}$ online store. Participants were instructed to use only the mouse to search and select for items. Also, participants were instructed to find each item and add it to their cart in the order listed.

Navigational efficiency was measured by the total time participants needed to complete all tasks and the total number of pages visited. Ergobrowser ${ }^{\mathrm{TM}}$ software [6] collected this data as well as Back, Forward, and breadcrumb clicks. An adaptation of the Satisfaction User Survey (SUS) instrument measured participants' satisfaction of the site [7]. 


\section{Results}

Table: 1

Average performance data for each condition

\begin{tabular}{llll}
\hline & $\begin{array}{l}\text { Condition I } \\
\text { Exposure \& } \\
\text { Instruction }\end{array}$ & $\begin{array}{l}\text { Condition II } \\
\text { Mere Exposure }\end{array}$ & $\begin{array}{l}\text { Condition III } \\
\text { No Exposure or } \\
\text { Instruction }\end{array}$ \\
\hline $\begin{array}{l}\text { Breadcrumb } \\
\text { Clicks }\end{array}$ & $9.92(1.66)$ & $6.07(4.56)$ & $5.62(4.75)$ \\
Back Clicks & $.31(.631)$ & $5.31(6.97)$ & $5.38(6.55)$ \\
Total Pages & $58.62(3.99)$ & $65.46(5.97)$ & $68.77(5.78)$ \\
$\begin{array}{l}\text { Total Time } \\
\text { (in sec.) }\end{array}$ & $560.46(93.01)$ & $724.08(264.69)$ & $832.54(170.37)$ \\
Satisfaction & $86.92(9.47)$ & $84.04(8.81)$ & $83.27(14.01)$ \\
\hline
\end{tabular}

$* \mathrm{p}<.05$

Total time to complete search tasks was significant $[\mathrm{F}(2,36)=6.79, \mathrm{p}<.01]$. Post hoc analysis showed Condition III (no exposure \& no instruction) to be slower than both Condition I and II. Satisfaction scores did not vary significantly [F $(2,36)=$ $.398, \mathrm{p}=.675$ ] Overall, participants in each condition were satisfied with the features and usability of the site.

\section{Conclusions}

Mere exposure alone did not significantly influence greater usage of the breadcrumb trail than the participants receiving no exposure. Minimal training did affect participants' usage of the breadcrumb trail and resulted in quicker completion times, fewer pages visited, and minimal use of the Back button. Exposure and instruction group completed all tasks $23 \%$ faster than the mere exposure group, and 33\% faster than the no exposure or instruction group. This could translate into increased productivity for employees that use websites with breadcrumb navigation for business, as well as overall time/cost savings for the company. Simple exposure combined with verbal instruction during a company intranet training session should be sufficient for employees to learn about this time-saving method of navigation.

\section{References}

[1]Bowler, D., Ng, W., \& Schwartz, P. (2001). Navigation bars for hierarchical websites. Retrieved 01/20/03 from University of Maryland http://www.otal.umd.edu/SHORE2001/navBar/index.html

[2]Maldonado, C. A., \& Resnick, M.L. (2002). Do common user interface design patterns improve navigation? Proceedings of the Human Factors and Ergonomics Society 46th Annual Meeting, 1315-1319.

[3]Lida, B., Hull, S. \& Pilcher, K. (2003). Breadcrumb navigation: An exploratory study of usage. http://psychology.wichita.edu/surl/usabilitynews/51/breadcrumb.htm

[4]Lida Rogers, B., \& Chaparro, B. (2003). Breadcrumb navigation: Further investigation of usage. http://psychology.wichita.edu/surl/usabilitynews/52 /breadcrumb.htm

[5]Zajonc, R. B. (1968). Attitudinal effects of mere exposure. Journal of Personality and Social Psychology Monographs, 9(2, Pt. 2).

[6]Ergobrowser ${ }^{\mathrm{TM}}$, Ergosoft Laboratories (C) 2001.

[7]Digital Equipment Corporation Limited (1986). System Usability Scale. Reading, United Kingdom: Digital Equipment Co. Ltd. @ 